\title{
Habitat size and the genetic structure of a cyclical parthenogen, Daphnia magna
}

\author{
J Vanoverbeke, K De Gelas and L De Meester \\ Laboratory of Aquatic Ecology, Katholieke Universiteit Leuven, Leuven, Belgium
}

\begin{abstract}
In populations of a cyclical parthenogen, the diversity of clonal lineages, derived from sexually produced eggs, declines during the parthenogenetic phase. Even though Daphnia magna populations from small ponds may harbour millions of individuals, we show that observed clonal and allelic diversity in populations from such small water bodies are lower than in populations from larger water bodies. Populations from small water bodies also show significant fluctuations in allele frequencies among years and a stronger
\end{abstract}

among-population genetic differentiation than populations inhabiting larger water bodies. Persistent founder effects can only explain part of these results. Our data link the population genetic structure of cyclical parthenogens to the size of the habitat and suggest that genetic drift is a more prominent feature of populations inhabiting small water bodies than previously thought.

Heredity (2007) 98, 419-426; doi:10.1038/sj.hdy.6800958; published online 28 March 2007

Keywords: Daphnia magna; habitat size; clonal diversity; allelic diversity; genetic drift; cyclical parthenogenesis

\section{Introduction}

In cyclical parthenogenetic cladocerans and rotifers, sexual reproduction is linked to the production of dormant stages that can survive unfavourable environmental conditions (King, 1980; Hebert, 1987). During favourable conditions, parthenogenesis is the predominant mode of reproduction, and clonal lineages are formed. Competition among clones during this parthenogenetic phase may erode clonal diversity, decreasing the number of clones present in the population or altering the relative frequencies of clonal lineages (Ruvinsky et al., 1986; Carvalho and Crisp, 1987). Daphnia species live in a wide variety of freshwater bodies, ranging from very small pools (a few square meters) to large lakes (Hebert, 1978; Fryer, 1991). Even within species, the variation in habitats occupied can be considerable. On the basis of clonal structure and stability as revealed by allozyme markers, Daphnia populations have traditionally been subdivided into three types: intermittent pond populations with frequent extinctions of the active population and heavy recruitment from the dormant egg bank, permanent pond populations which are much more stable and are assumed to only sporadically engage in sexual reproduction and recruitment of new genotypes from the dormant egg bank (Hebert, 1978, 1987), and lake populations (Mort and Wolf, 1986; Jacobs, 1990). Although intermittent pond populations and lake populations are characterized by a high clonal diversity (tens of

Correspondence: Dr J Vanoverbeke, Laboratory of Aquatic Ecology, Katholieke Universiteit Leuven, Ch. Deberiotstraat 32, Leuven 3000, Belgium.

E-mail: joost.vanoverbeke@bio.kuleuven.be

Received 9 February 2006; revised 19 December 2006; accepted 16 February 2007; published online 28 March 2007 detectable clones in a standard sample of 50-100 individuals) and relatively stable genotype frequencies, permanent pond populations show a much lower clonal diversity (only a few detectable clones) and pronounced temporal shifts in clonal composition (probably associated with recruitment from the egg bank; reviews in Hebert, 1987; De Meester, 1996).

Differences among these three types of water bodies can be expressed in terms of length of the parthenogenetic phase and size of the habitat (De Meester et al. 2006). Although the effect of duration of the growing season (parthenogenetic reproduction) on the genetic composition of cyclical parthenogenetic populations is easily appreciated when comparing, for example, intermittent and permanent pond populations, size of the habitat has never been looked at explicitly. Yet, size of the habitat may play a significant role in determining the genetic structure of cyclical parthenogenetic populations, as is indicated by the difference in genetic structure between pond and lake populations.

There are several a priori reasons to expect a positive relationship between habitat size and clonal diversity of a population of cyclical parthenogens. First, although even in small ponds hundreds to thousands of clones will hatch from the egg bank at the beginning of the growing season (De Meester et al., 2006), smaller ponds are expected to have a smaller stock of dormant eggs and hence to have a lower total recruitment of clones from the dormant egg bank. Second, small ponds harbour smaller populations than large lakes, making a population with an equal diversity of clones more vulnerable to extinction of clones, as each clone will be represented by fewer individuals. Higher starting variation and lower extinction rates in larger water bodies may together prolong the period needed for clonal diversity to drop to levels comparable to populations from smaller ponds. Third, large water bodies harbour more niches, enabling 
stable coexistence of more genotypes. We here relate clonal diversity to habitat size in natural populations of the cyclical parthenogen D. magna, and we investigate the impact of this relation on allelic diversity and on genetic drift within and among populations.

\section{Materials and methods}

In total, we sampled 20 natural D. magna populations. Of these populations, 17 are situated in Belgium and three populations are from large water bodies situated in Hungary (Table 1). Population genetic data on seven of the 17 Belgian populations were incorporated in the study on interpopulational genetic differentiation by Vanoverbeke and De Meester (1997). Ten populations (seven Belgian and three Hungarian; see Table 1) were sampled twice with a time interval ranging from 1 to 5 years. All sampled populations inhabit shallow water bodies ( $<2 \mathrm{~m}$ depth). Although most of the sampled populations periodically engage in extensive sexual reproduction $(\mathrm{CS}, \mathrm{CB}, \mathrm{DV}, \mathrm{FP}, \mathrm{OM} 1, \mathrm{OM} 2, \mathrm{OM} 3$, De Meester and Vanoverbeke, 1999; PB, EK, Vanoverbeke and De Meester, 1997; OH, SP ponds, personal observation) and often cannot be detected in the water column, in most of the populations mild winters allow individuals to survive till the next spring. We have no direct data on hatching in the field except for the OM ponds (unpublished data); yet, we assume that in most populations, at least in early spring at the onset of the growing season, substantial hatching occurs from the local resting egg bank. The hatching data from the OM ponds (unpublished data) indeed indicate that a major bout of hatching occurs in April; hence, we defined the beginning of April as the start of the growing season for the Belgian populations and calculated the time to sampling (TTS, expressed in months; Table 1) as the time elapsed from the beginning of April to the moment of sampling. An exception was made for the SP ponds which are very shallow $(<0.5 \mathrm{~m})$, intermittent prairie ponds and were sampled shortly after they refilled with water in late summer. Some of the other populations (e.g. DV) may also dry out during summer, but we only have evidence for the SP ponds that they were sampled shortly after refilling.

As a measure of habitat size, we used surface area (SA) of the habitat. SA can be expected to be a good estimator of habitat size for the sampled populations, as D. magna tends to be found in the whole water body of these shallow ponds and lakes. The SA of the populations ranged from a few square meters to 200 ha (Table 1 ).

To avoid interference from genotype-dependent habitat selection (Weider, 1984; De Meester et al., 1994), the whole water column (top to bottom) was sampled using a dip net (mesh size, $200 \mu \mathrm{m}$ ). Adult female Daphnia were picked out randomly and stored at $-80^{\circ} \mathrm{C}$ until further analysis. From each population, between 33 and 60 animals were successfully screened for genetic variation at four allozyme loci (GPI, EC 5.3.1.9; MPI, EC 5.3.1.8; AAT, EC 2.6.1.1; $\mathrm{MDH}, \mathrm{EC}$ 1.1.1.37), using cellulose acetate gel electrophoresis following the methods of

Table 1 D. magna populations studied (ordered by size of the habitat), showing name and abbreviation, location (village or town and country: $\mathrm{B}=$ Belgium, $\mathrm{H}=$ Hungary), surface area (SA; in ha), sampling date, time to sampling (TTS; only for the Belgian populations), sample size ( $N$ ), clonal diversity $(\mathrm{CD})$ and expected heterozygostiy $\left(H_{\mathrm{e}}\right)$

\begin{tabular}{|c|c|c|c|c|c|c|c|c|}
\hline Name & Location & $S A$ & Date & TTS & $\mathrm{N}$ & $C D$ & & $\mathrm{H}_{e}$ \\
\hline Pond Botanic Garden (PB) & Gent (B) & 0.0004 & 03/07/92 & 3 & 45 & 1.00 & + & 0.13 \\
\hline Sheep Pond 1 (SP1) & Haasrode (B) & 0.0025 & $17 / 09 / 96$ & 0.5 & 59 & 2.36 & & 0.12 \\
\hline Sheep Pond 3 (SP3) & Haasrode (B) & 0.0025 & $16 / 10 / 96$ & 1.5 & 60 & 17.31 & & 0.33 \\
\hline Sheep Pond 4 (SP4) & Haasrode (B) & 0.0025 & $17 / 09 / 96$ & 0.5 & 60 & 17.56 & & 0.37 \\
\hline \multirow[t]{2}{*}{ Tersaart Pond (TE) } & Duisburg (B) & 0.018 & $15 / 05 / 00$ & 1.5 & 60 & 3.84 & + & 0.28 \\
\hline & & & 13/07/01 & 3.5 & 60 & 1.94 & + & 0.32 \\
\hline Ganzepoel Pond (GA) & Duisburg (B) & 0.02 & $15 / 09 / 00$ & 5.5 & 39 & 3.68 & + & 0.22 \\
\hline \multirow[t]{2}{*}{ Oude Meren 5 (OM5) } & Heverlee (B) & 0.025 & $19 / 07 / 00$ & 3.5 & 60 & 8.62 & + & 0.48 \\
\hline & & & 10/07/01 & 3 & 60 & 2.47 & + & 0.45 \\
\hline Citadelpark Small Pond (CS) & Gent (B) & 0.03 & 20/10/92 & 6.5 & 64 & 1.25 & + & 0.32 \\
\hline Citadelpark & Gent (B) & 0.15 & 06/07/92 & 3 & 48 & 1.24 & + & 0.18 \\
\hline Big Pond (CB) & & & $20 / 05 / 96$ & 1.5 & 58 & 19.77 & & 0.42 \\
\hline Eendekooi (EK) & Woumen (B) & 0.4 & 03/08/92 & 4 & 47 & 3.70 & + & 0.38 \\
\hline Fish Pond (FP) & Woumen (B) & 0.55 & 03/08/92 & 4 & 42 & 5.48 & + & 0.49 \\
\hline Driehoeksvijver (DV) & Heusden (B) & 0.75 & $30 / 07 / 92$ & 4 & 43 & 10.94 & + & 0.42 \\
\hline \multirow[t]{2}{*}{ Oude Meren 1 (OM1) } & Heverlee (B) & 1.20 & 04/07/96 & 3 & 60 & 3.96 & + & 0.33 \\
\hline & & & $10 / 07 / 01$ & 3 & 55 & 25.42 & & 0.48 \\
\hline \multirow[t]{2}{*}{ Oude Meren 2 (OM2) } & Heverlee (B) & 2.53 & $04 / 07 / 96$ & 3 & 59 & 14.94 & + & 0.48 \\
\hline & & & $26 / 07 / 00$ & 4 & 44 & 5.20 & + & 0.39 \\
\hline \multirow[t]{2}{*}{ Oude Meren 3 (OM3) } & Heverlee (B) & 1.84 & 04/07/96 & 3 & 60 & 11.27 & + & 0.48 \\
\hline & & & $15 / 05 / 00$ & 1.5 & 60 & 18.22 & + & 0.45 \\
\hline \multirow{2}{*}{ Oud Heverlee Pond $(\mathrm{OH})$} & Oud-Heverlee (B) & 8.88 & $01 / 07 / 96$ & 3 & 60 & 18.37 & & 0.41 \\
\hline & & & $13 / 07 / 01$ & 3.5 & 40 & 17.78 & & 0.39 \\
\hline Lake Blankaart (LB) & Woumen (B) & 30 & $25 / 05 / 94$ & 2 & 41 & 12.64 & + & 0.51 \\
\hline \multirow[t]{2}{*}{ Feherszik (FE) } & Tiszavasvári (H) & 110 & $15 / 05 / 00$ & & 33 & 6.08 & & 0.26 \\
\hline & & & 13/05/01 & & 60 & 17.09 & & 0.33 \\
\hline \multirow[t]{2}{*}{ Zabszek (Za) } & Fülöpszállás (H) & 120 & 06/07/00 & & 60 & 11.76 & & 0.30 \\
\hline & & & 08/05/01 & & 60 & 8.00 & & 0.24 \\
\hline \multirow{2}{*}{ Kelemensek (KE) } & Fülöpszállás (H) & 200 & $15 / 05 / 00$ & & 60 & 5.58 & & 0.23 \\
\hline & & & 08/05/01 & & 60 & 5.76 & & 0.21 \\
\hline
\end{tabular}

Deviations of CD from H-W expectations: + indicates $P<0.05$ at the tablewide level, after sequential Bonferroni correction (Rice, 1989). 
Hebert and Beaton (1989). Using the genotype obtained at each locus, we constructed multilocus genotypes for all sampled individuals. Clonal diversity (CD) in each population was calculated as the inverse of the Simpson index (Lande, 1996):

$$
\frac{1}{\sum_{i} p_{i}^{2}}
$$

with $p_{i}$ being the relative frequency of the $i$ th multilocus genotype. Because multiple clones may have an identical genotype at the analyzed loci, this is only a lower limit for the real clonal diversity. We tested for deviations of the clonal diversity as observed by our allozyme markers from Hardy-Weinberg $(\mathrm{H}-\mathrm{W})$ expectations using a randomization test (using the software module Hwclon; De Meester and Vanoverbeke, 1999). This test calculates deviations of the observed clonal diversity from the clonal diversity expected in a number of permutations of the original sample. That is, at each locus, the alleles are randomly divided over the individuals to create a new sample of the same size and with the same number of copies of each allele (De Meester and Vanoverbeke, 1999). Significant deviations from H-W expectations indicate that the real number of clones (genome wide) in the sample is limited and in good agreement with the detected number of clones (multilocus genotypes). As a measure of allelic diversity, we calculated average expected heterozygosity, $H_{\mathrm{e}}$, over the analyzed loci using TFPGA (Miller, 1997).

Because of large genetic differences among Belgian and Hungarian populations (substitution of some alleles and large differences in allele composition, KDG unpublished results), the Hungarian populations were only included in the analysis on within-population among-year genetic differentiation (YTY $F_{\mathrm{ST}}$, see further). They were not included in the analysis of the relation between clonal diversity or allelic diversity versus SA nor in the analysis of genetic differentiation among populations versus SA.

For the Belgian populations, we performed a multiple regression analysis with $\mathrm{CD}$ as dependent variable and SA of the habitat (logarithmically transformed), TTS and $H_{\mathrm{e}}$ as independent variables. TTS was incorporated in the model because clonal erosion and its effect on the observed clonal diversity of the populations is expected to increase with the period of clonal selection since the hatching from sexual eggs, and we wanted to correct for this in the analysis of the effect of SA on CD. Likewise, allelic diversity may have an effect on CD. Indeed, CD as measured by multilocus genotypes is dependent on the allelic diversity of the markers (a higher allelic diversity gives more possible multilocus genotypes). In its turn, allelic diversity is determined by the genetic structure and events in previous growing seasons as well as by the clonal diversity in the present growing season, which we want to investigate. By correcting for $H_{\mathrm{e}}$ in the relationship between CD and SA, we can correct for the reduced resolution of observed clonal diversity at low allelic diversity in our results. For those populations where data were available for 2 years, we used the average over years. We excluded, however, the SP ponds from the analysis because they were sampled shortly after they refilled with water in late summer (and thus shortly after being entirely reconstituted from resting eggs). Although we take into account TTS in the analysis, preliminary analyses showed that the SP ponds behaved as outliers and strongly influenced our results. Other populations with short TTS on one of the sampling dates were averaged over sampling dates or showed significant deviations from $\mathrm{H}-\mathrm{W}$ expectations (evidence for limited diversity of surviving clones since hatching from resting eggs) and were thus included in the analysis. Multiple regression (with log transformation of SA) was performed using Statistica 6.0 (StatSoft Inc., 2001). Before the multiple regression, we calculated pairwise correlations among the three independent variables SA, TTS and $H_{\mathrm{e}}$.

To investigate directly the effect of habitat size on allelic diversity within populations, we also performed a linear regression on the relation between $H_{\mathrm{e}}$ and SA (logarithmically transformed). Whereas the effect of SA on CD corrected for $H_{\mathrm{e}}$ will be most obvious after a prolonged period of clonal selection, effects of SA on allelic diversity (especially presence/absence of alleles) are taken along to the next sexual generation and are thus accumulated over growing seasons. They should be distinguishable at any period of the current growing season; for that reason, the SP ponds were included in this analysis.

For each of the 10 populations that were sampled twice (i.e. including the Hungarian populations), genetic differentiation between sampling dates within populations was analyzed. We used a permutation test (Raymond and Rousset, 1995) in TFPGA (Miller, 1997) to determine the significance of genetic differentiation among samples within each population and calculated year-to-year (YTY) $F_{\mathrm{ST}}$ values $\left(F_{\mathrm{ST}}\right.$, Weir and Cockerham, 1984) using TFPGA (Miller, 1997). YTY $F_{\mathrm{ST}}$ values were plotted against SA of the habitat (both variables logarithmically transformed) and analyzed using linear regression, to investigate the influence of habitat size on the YTY genetic differentiation within populations. Prior to the linear regression we tested for a correlation between log SA and time between two sampling events within each population.

To test whether habitat size has an influence on genetic differentiation among populations, we investigated the relationship between mean SA for each pair of populations and pairwise genetic differentiation $\left(F_{\mathrm{ST}}\right.$; Weir and Cockerham, 1984; calculated with GENETIX, Belkhir et al., 1996-2004). To make sure the observed patterns between $F_{\mathrm{ST}}$ and SA were not confounded with geographical patterns, a partial Mantel test (Bonnet and Van de Peer, 2002) was used to correlate genetic differentiation with mean SA, while controlling for geographic distance among populations. This test performs a regular Mantel test on the residuals of $F_{\mathrm{ST}}$ and SA over geographic distance. For water bodies that were sampled twice, we only considered the first sampling date. Because the strong genetic divergence between the Belgian and Hungarian populations would disturb any pattern resulting from habitat size, the Hungarian populations were omitted from this analysis.

\section{Results}

For 17 out of the 30 samples, significant deviations of multilocus genotype frequencies from $\mathrm{H}-\mathrm{W}$ expectations were observed, resulting in a reduction of the observed CD from the expected CD (Table $1 ; P<0.05$; correcting 
for errors at the table-wide level by sequential Bonferroni, following Rice, 1989). Of the 13 samples without significant deviations of multilocus genotype frequencies from $\mathrm{H}-\mathrm{W}$ expectations, only four samples came from water bodies with a SA less than 1 ha. Three of these samples were taken from the very small Sheep ponds, which are known to dry out during summer. These populations were sampled shortly after the ponds refilled with water and hence, shortly after hatching from the dormant egg bank.

From the pairwise correlations between SA (logtransformed), TTS and $H_{\mathrm{e}}$, only the correlation between SA and $H_{\mathrm{e}}$ was significant $(N=14, R=0.80, P=0.001$; SA versus TTS: $R=-0.32, P=0.27$; TTS versus $H_{\mathrm{e}}$ : $R=-0.26, \quad P=0.36$ ). When looking at the multiple regression, there was only a significant partial effect of $\mathrm{SA}$ on CD (Table 2 and Figure 1). Observed clonal diversity was lower in small ponds than in larger water bodies, even when $H_{\mathrm{e}}$ and TTS were accounted for. Plotting $H_{\mathrm{e}}$ against $\log$ SA for all Belgian populations (including the SP ponds) also resulted in a highly significant positive relationship (Figure 2; $N=17$, $R^{2}=0.57, P<0.001$ ).

Five out of 10 populations showed significant genetic differentiation between samples taken in different years (YTY $F_{\mathrm{ST}}$, all $P<0.001$; Figure 3 ). The remaining five populations showed no significant YTY genetic differentiation, indicating relatively stable allele frequencies between the two sampling dates. Although the time between two sampling events within one population ranged from 1 to 5 years, there was no correlation with $\log \mathrm{SA}(N=10, R=-0.13, P=0.72)$. YTY $F_{\mathrm{ST}}$ ranged from 0.004 to 0.13 , and was negatively related to SA (both variables logarithmically transformed) (Figure 3; $N=10$, $R^{2}=0.83, P<0.001$ ).

Finally, populations inhabiting small ponds tend to be more genetically differentiated than populations inhabiting larger water bodies, as revealed by a significant negative correlation between pairwise $F_{\mathrm{ST}}$ and $\log$ (mean SA) (partial Mantel test controlling for geographic distance (log-transformed): $N=17, R^{2}=0.20, P<0.001$; Figure 4).

\section{Discussion}

Our results indicate that Daphnia populations inhabiting small water bodies show (1) a lower observed clonal diversity, (2) a lower expected heterozygosity, (3) more pronounced YTY fluctuations in allele frequencies within populations, and (4) higher among population genetic differentiation, compared with Daphnia populations inhabiting larger water bodies. Since small water bodies

Table 2 Results of the multiple regression analysis ( $\beta=$ adjusted regression coefficients, $\mathrm{B}=$ regression coefficients)

\begin{tabular}{lrrrc}
\hline & \multicolumn{1}{c}{$\beta$ (s.e.) } & \multicolumn{1}{c}{$\mathrm{B}$ (s.e.) } & $\mathrm{t}(10)$ & $\mathrm{P}$ \\
\hline Intercept & & $20.35(6.09)$ & 3.34 & $\mathbf{0 . 0 0 7}$ \\
Log(SA) & $0.94(0.26)$ & $4.06(1.12)$ & 3.62 & $\mathbf{0 . 0 0 5}$ \\
TTS & $-0.29(0.16)$ & $-1.29(0.71)$ & -1.81 & 0.090 \\
$H_{\mathrm{e}}$ & $-0.27(0.26)$ & $-13.73(13.05)$ & -1.05 & 0.318 \\
\hline
\end{tabular}

General: $R^{2}$ adjusted $=0.69, \mathrm{~F}_{(3,10)}=10.373, P=0.002$.

Significant $P$-values are indicated in bold.
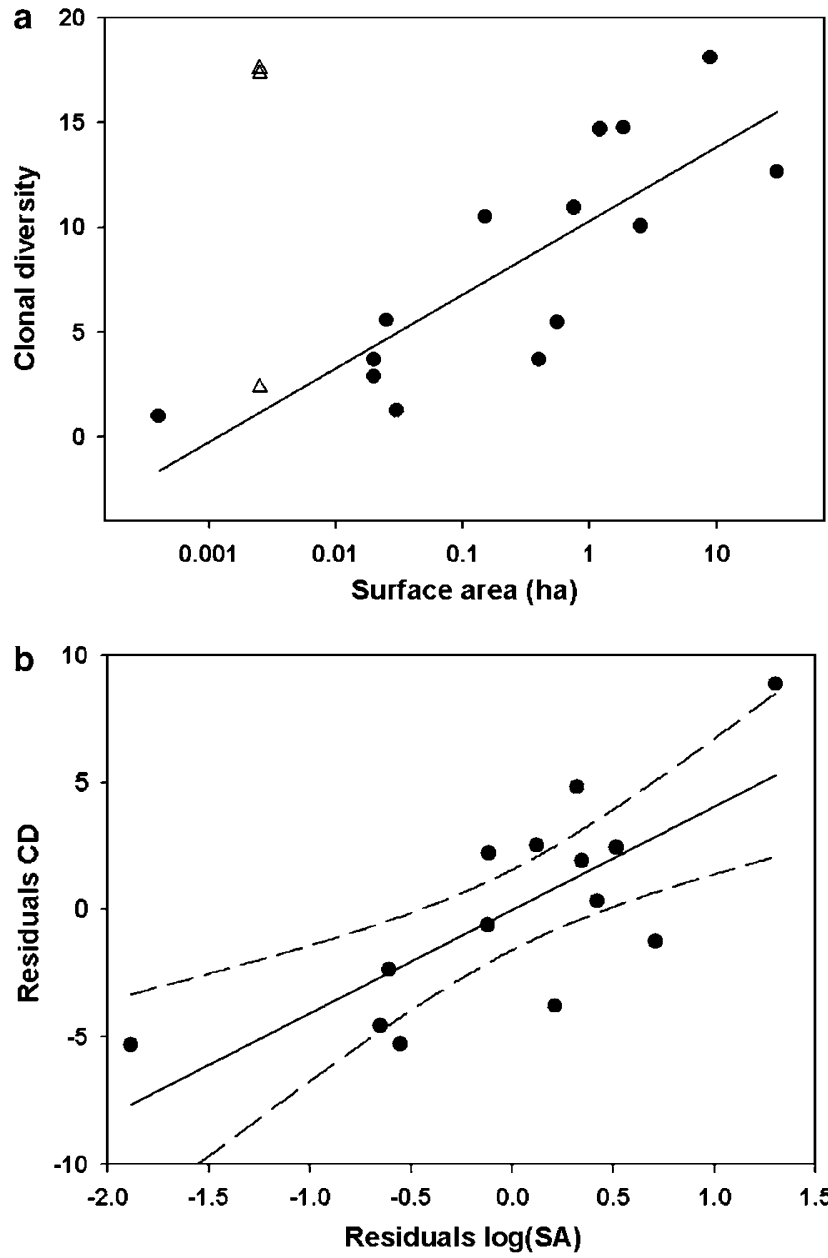

Figure 1 Clonal diversity of D. magna populations versus SA of the habitat in hectares. (a) Data uncorrected for TTS and $H_{\mathrm{e}}$. Filled circles: populations included in the multiple regression analysis; open triangles: populations excluded from the multiple regression analysis; the line represents the regression of $C D$ over SA not corrected for TTS or $H_{\mathrm{e}}$. (b) Residuals of $\log (\mathrm{SA})$ and CD over TTS and $H_{\mathrm{e}}$ (only populations included in the multiple regression analysis). The line represents the regression $( \pm 95 \%$ confidence limits) over the residuals.

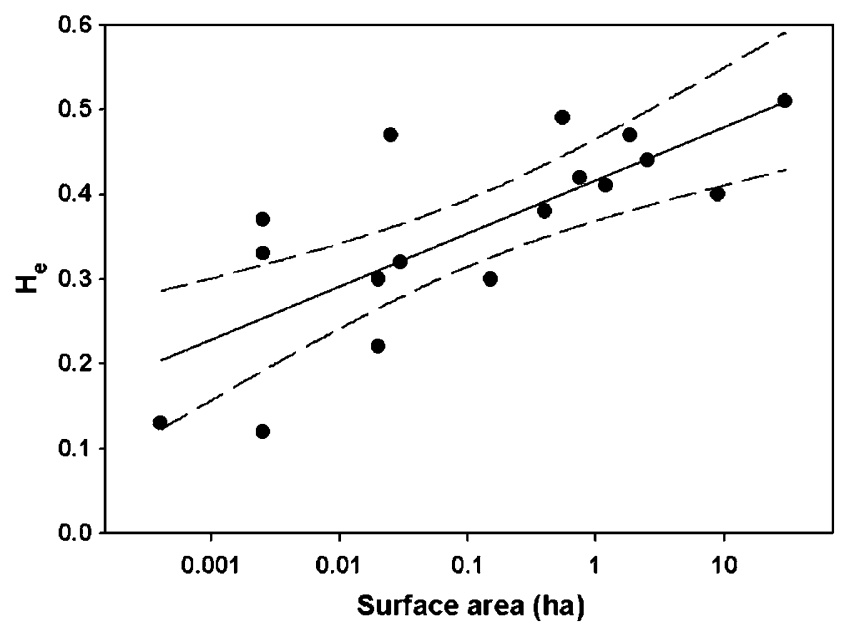

Figure 2 Expected heterozygosity $\left(H_{\mathrm{e}}\right)$ of $D$. magna populations versus SA of the habitat (in hectares). 


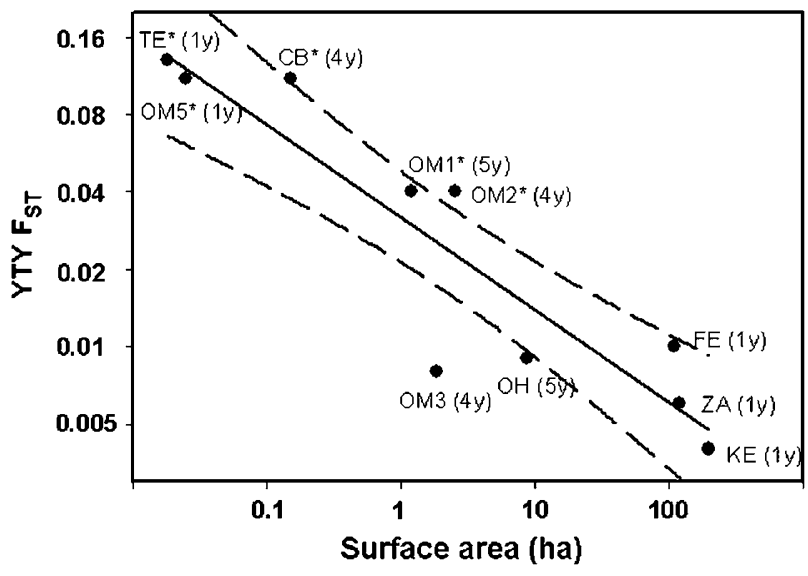

Figure 3 Among year genetic differentiation (YTY $F_{\mathrm{ST}}$ ) in D. magna populations versus SA of the habitat (in hectares). Population names and sampling interval are indicated on the graph (see also Table 1). *Indicates significant differentiation among two sampling dates.

are expected to be colonized by a smaller number of propagules than large water bodies, persistent founder effects could cause the reduced genetic diversity within and enhanced genetic differentiation among populations inhabiting small water bodies (Boileau et al., 1992; De Meester et al., 2002). Whereas clonal diversity as observed by allozyme markers is strongly dependent on the allelic diversity of the markers, however, founder effects cannot explain the lower CD observed in small compared to large water bodies when correcting for allelic diversity $\left(H_{\mathrm{e}}\right.$, multiple regression) nor the increased YTY genetic differentiation within populations from small water bodies. The significant regression of SA on $\mathrm{CD}$ when correcting for $H_{\mathrm{e}}$ indicates that the reduced $\mathrm{CD}$ in smaller ponds is not only the result of a lower allelic diversity but that there is also a direct effect of SA on $\mathrm{CD}$. When recruiting from the egg bank at the start of the growing season, even in very small populations hundreds to thousands of clones will hatch simultaneously (De Meester et al., 2006) and the genetic composition of the hatchlings will be in close agreement with $\mathrm{H}-\mathrm{W}$ expectations. This is, for example, evident from the observation of high clonal diversity in some of the populations from small ponds that were sampled shortly after the onset of the growing season. In cyclical parthenogenetic populations, competition among clonal lineages, however, will erode clonal diversity during the phase of parthenogenetic reproduction (Ruvinsky et al., 1986), which will eventually result in deviations from $\mathrm{H}-\mathrm{W}$ expectations. Observations of reduction in genetic (clonal) diversity during the course of the growing season have been reported for cladocerans (Carvalho and Crisp, 1987; De Meester et al., 2006), rotifers (Gómez and Carvalho, 2000; Ortells et al., 2006) and aphids (Rhomberg et al., 1985; Sunnucks et al., 1997). Survival of clones during winter will even enforce this reduction in clonal diversity after recruitment from the egg bank in early spring, as clones that survived winter have a head start in reproduction over newly hatched clones. Although the current data do not allow the direct assessment of a reduction of CD with time (the populations were never sampled repeatedly within 1 year), our results indicate that the observed impact of
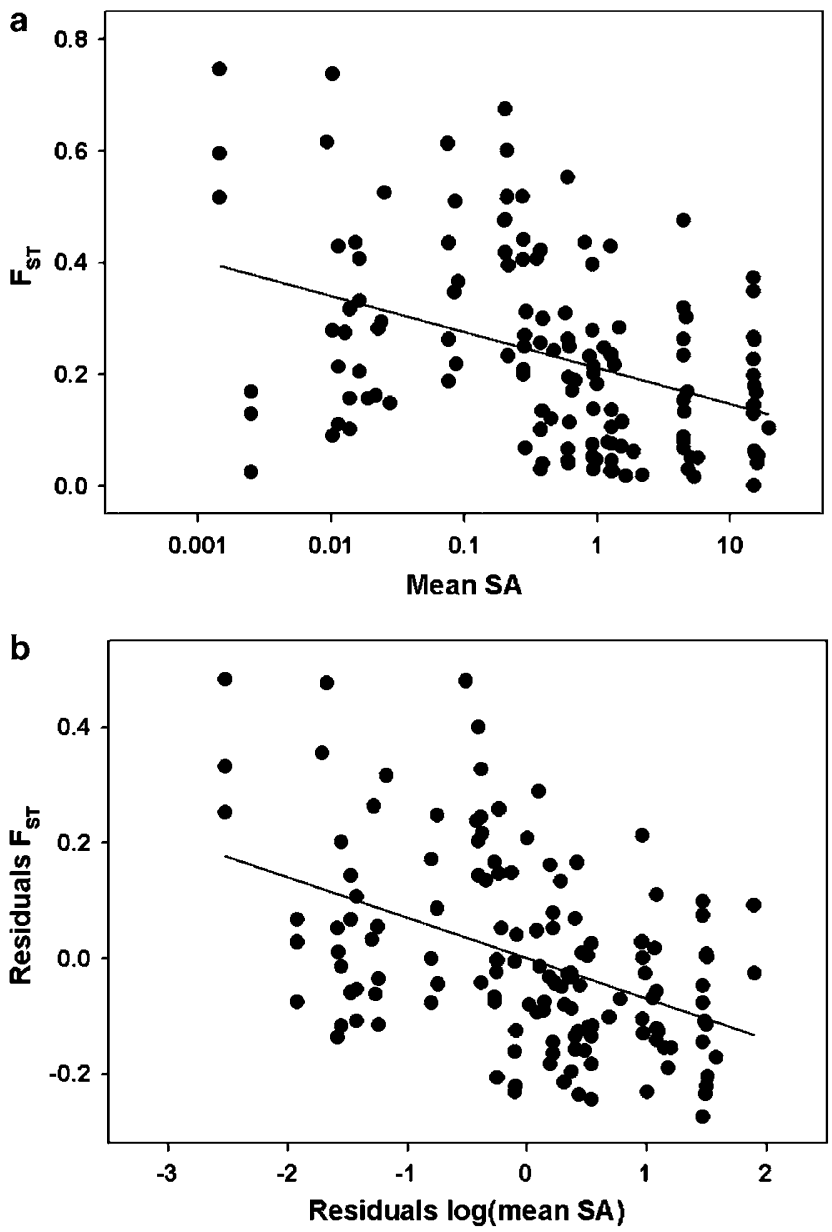

Figure 4 (a) Genetic differentiation $\left(F_{\mathrm{ST}}\right)$ plotted against mean SA for all pairwise combinations of 17 Belgian D. magna populations. For populations sampled on two dates, only the first sample was considered. The Hungarian populations were omitted from the analysis. The line represents the regression of $F_{\mathrm{ST}}$ over mean SA not corrected for geographic distance. (b) Residuals of $F_{\mathrm{ST}}$ on geographic distance versus residuals of mean $\log (\mathrm{SA})$ on geographic distance, used for the partial Mantel test. The line represents the regression over the residuals.

clonal erosion is more obvious in populations inhabiting small compared to large water bodies, with lower observed $\mathrm{CD}$ and more significant deviations from $\mathrm{H}-$ $\mathrm{W}$ expectations in populations from small versus large water bodies. Also in aphids, several studies revealed low clonal diversity in populations living in small patches of host plants (Rhomberg et al., 1985; Hebert et al., 1991).

As mentioned, we do not have exact data on the length of the asexual growing period for most of the populations studied, as we have no data on the balance between survival of clones through winter and new input of clones from hatching in early spring. In LB, for example, although it is a big population and TTS is only estimated to be about 2 months, the CD is significantly deviating from $\mathrm{H}-\mathrm{W}$ expectations (see Table 1), indicating that significant clonal erosion has already taken place. Likely, part of the population at the moment of sampling consisted of clones that survived winter. The same can be said for OM1 where, although we have clear indications of substantial hatching in early spring 
(unpublished data), the clonal diversity is consistently low over a period of 2 years around the first sampling date (1996-1997; see De Meester et al., 2006). Although the period of asexual reproduction before sampling will certainly play a role in our data, there is, however, no reason to expect a consistent pattern of increasing permanency of the populations with decreasing SA, which could interfere with our results. If anything, the larger water bodies, such as LB, could be expected to contain the most permanent populations (they are, for instance, less prone to drying out or complete freezing of the water body), which would give a pattern between CD and SA opposite to the one we observe. Admittedly, if populations from smaller ponds do over winter, fewer clones will likely survive (see below) compared with populations from the larger water bodies, contributing to the differences in clonal diversity between small and large water bodies.

The positive relation between $\mathrm{CD}$ and habitat size does not imply that clonal erosion, and especially clonal selection (one of the forces causing clonal erosion) is stronger in small compared to large water bodies. As populations inhabiting small water bodies are expected to have a lower recruitment of clones from the dormant egg bank than populations inhabiting large water bodies, clonal diversity will be reduced to lower levels in small than in large water bodies when selection strengths are similar. As a result, clonal diversity after a few months of clonal selection in populations from large compared to small water bodies is more likely to still be high and above the level causing significant deviations of multilocus genotype frequencies from $\mathrm{H}-\mathrm{W}$ expectations. There is one obvious mechanism, however, by which the decline in clonal diversity through time may be slower in large compared to small water bodies: with a comparable clonal structure, the larger population sizes in larger water bodies may further reduce the probability of extinction of less frequent clones. Although rare clones do not affect clonal diversity much, their survival may aid in preserving diversity over longer periods of time in water bodies, for example, with fluctuating selection pressures.

Since each clonal group recognized by allozyme electrophoresis may consist of different 'real' clones (genome wide), we are not able to calculate the true clonal diversity of the studied populations. Nevertheless, in populations with strong deviations from $\mathrm{H}-\mathrm{W}$ expectations, $C D$ as revealed by the used markers may be a good approximation of the real clonal diversity of the population. In the case of significant deviations even with the relatively low resolution of our allozyme markers, CD is below the saturation level of the markers and the probability that two random multilocus genotypes are the same is very low (the average percentage of polymorphic loci (99\% level) was $91 \%$ for the samples of the Belgian populations and $96 \%$ for the samples of the Hungarian populations, and the average number of alleles per locus was 2.1 and 2.3, respectively). This means that in the smallest of the studied water bodies (SA <0.05 Ha), the true clonal diversity may actually have been reduced to less than 10 . Whereas thousands of genotypes may have hatched from the egg bank at the beginning of the growing season (egg bank sizes are often $10^{4}-10^{5}$ eggs per square meter; see Brendonck and De Meester, 2003), most of the genes of the next sexual generation will be contributed by just a few clones.
The reduced level of clonal diversity in populations from small water bodies has non-trivial consequences with respect to drift phenomena on the allelic level. This genetic drift is associated with the cyclical parthenogenetic reproduction mode of Daphnia, because it is due to the low level of clonal diversity rather than to low census population sizes. Indeed, a small but productive habitat $\left(100 \mathrm{~m}^{2}\right.$; average depth $\left.1 \mathrm{~m}\right)$ may easily contain $1 \times 10^{6}$ Daphnia individuals (density $10 \mathrm{l}^{-1}$ ). Effective population size, however, is a function of clonal diversity (Lynch, 1984; King, 1993; De Meester et al., 2006) which may only be a few clones. Heritable variation in key life history and other traits that may strongly impact fitness in relation to (changing) environmental conditions is high in Daphnia (Lynch, 1984; Tessier et al., 1992; De Meester, 1996) and very pronounced changes in genotype frequencies have been observed in population genetic surveys of Daphnia populations (reviewed by Hebert, 1987). This indicates the power of successful clones to rapidly increase in frequency during the course of the growing season. Assuming random mating, the association of neutral markers with successful genotypes during a given growing season is determined by chance. One then expects random among growing season fluctuations in allele frequencies at neutral markers for populations where the clonal diversity drops to low levels at the moment of sexual reproduction. Indeed, allele frequencies at the start of the next growing season (after sexual reproduction and hatching of the resting eggs) will not necessarily resemble the frequencies at the start of the previous growing season but will resemble the frequencies among the clones involved in sexual reproduction at the end of the previous growing season. Our results strongly suggest that this drift-like hitchhiking of alleles at neutral markers is more prominent in populations inhabiting smaller than larger water bodies. Our results do not only reveal a positive relation between allelic diversity of the Daphnia populations and SA of their habitat, but also show that Daphnia populations inhabiting small water bodies may exhibit substantial among-year fluctuations in allelic frequencies. Although founder effects may, as mentioned, play a considerable role in determining allelic diversity, the reduced $H_{\mathrm{e}}$ observed in small compared to large water bodies may thus in part also result from genetic drift associated with the clonal structure of the populations. Whereas a reduction of the observed $C D$ is most obvious near the end of the growing season, the effect of SA on $H_{\mathrm{e}}$ is accumulated over the growing seasons and visible at any period of the ongoing growing season. Although the SP ponds, for example, which established from the egg bank shortly before sampling, do not indicate any influence of clonal erosion on observed $\mathrm{CD}, H_{\mathrm{e}}$ of these populations fits the observed pattern of a reduced allelic diversity in populations from small compared to large water bodies. Similar to the loss of allelic diversity through genetic drift, the observed among-year fluctuations in allele frequencies (YTY $F_{\mathrm{ST}}$ ) of populations inhabiting small water bodies can be explained by a hitchhiking phenomenon of the markers with successful clones during the period of clonal reproduction (Lynch and Spitze, 1994; Vanoverbeke and De Meester, 1997). The YTY fluctuations in allelic frequencies are indeed not observed in populations from large water bodies.

The observed drift patterns in Daphnia populations inhabiting small water bodies not only influence genetic 
variation within populations but also genetic divergence among populations. Cyclical parthenogenetic zooplankton populations are characterized by marked gene frequency divergence (see reviews in Hebert, 1987; Boileau et al., 1992; De Meester, 1996; De Meester et al., 2002). This genetic differentiation is mostly ascribed to the founding of populations by only a few individuals and to the persistence of these founder effects for many generations (Boileau et al., 1992). Furthermore, gene flow among populations is likely to be reduced by priority effects and rapid monopolization of resources (De Meester et al., 2002). Our results suggest, however, that the genetic divergence among populations can also be inflated by random shifts in allele frequencies in cyclical parthenogenetic populations in which clonal diversity drops to low levels (see also Vanoverbeke and De Meester, 1997). If the high levels of genetic differentiation would be the result of founder effects alone, one would not expect the marked among-year shifts in allele frequencies within populations from small water bodies reported by the present study. These random shifts in allele frequencies will inevitably lead to an enhanced genetic differentiation among populations from small populations as observed in a survey using neutral markers.

We conclude that size of the habitat can have an important impact on the genetic structure of cyclical parthenogenetic Daphnia populations. Whereas founder events and permanency of the habitat have long been appreciated as factors determining within- and amongpopulation genetic variation in cyclical parthenogens, size of the habitat and its impact on clonal diversity may play a more prominent role than previously expected. Not only could persistent founder effects be more important in small compared to large water bodies, their effect may also be strengthened by a reduced clonal diversity, resulting in an enhancement of genetic drift. This in turn will lead to a further reduction in allelic diversity within and a further increase in genetic differentiation among populations, as well as in pronounced differences in allele frequencies within populations among years.

\section{Acknowledgements}

This research was supported by projects OT/00/14 and OT/04/23 of the KULeuven Research Fund, BIL project 99/17 (cooperation Flanders-Hungary), and ESF Eurodiversity project BIOPOOL (nationally funded by Belspo and FWO). We thank Dr L Forro for help with sampling the Hungarian D. magna populations, and Dr S Declerck for providing valuable advice in analyzing our data.

\section{References}

Belkhir K, Borsa P, Chikhi L, Raufaste N, Bonhomme F (19962004). GENETIX 4.05, logiciel sous Windows TM pour la génétique des populations. Laboratoire Génome, Populations, Interactions, CNRS UMR 5000. Université de Montpellier II: Montpellier, France.

Boileau MG, Hebert PDN, Schwartz SS (1992). Non-equilibrium gene frequency divergence: persistent founder effects in natural populations. J Evol Biol 5: 25-39.

Bonnet E, Van de Peer Y (2002). ZT: a software tool for simple and partial Mantel tests. J Stat Software 7: 1-12.
Brendonck L, De Meester L (2003). Egg banks in freshwater zooplankton: evolutionary and ecological archives in the sediment. Hydrobiologia 491: 65-84.

Carvalho GR, Crisp DJ (1987). The clonal ecology of Daphnia magna (Crustacea: Cladocera) I. Temporal changes in the clonal structure of a natural population. J Anim Ecol 56: 453-468.

De Meester L (1996). Local genetic differentiation and adaptation in freshwater zooplankton populations: patterns and processes. Ecoscience 3: 385-399.

De Meester L, Gomez A, Okamura B, Schwenk K (2002). The monopolisation hypothesis and the dispersal-gene flow paradox in aquatic organisms. Acta Oecol 23: 121-135.

De Meester L, Vandenbeghe J, Desender K, Dumont HJ (1994). Genotype-dependent daytime vertical distribution of Daphnia magna in a shallow pond. Belgian J Zool 124: 3-9.

De Meester L, Vanoverbeke J (1999). An uncoupling of male and sexual egg production leads to reduced inbreeding in the cyclical parthenogen Daphnia. Proc R Soc B 266: 2471-2477.

De Meester L, Vanoverbeke J, De Gelas K, Ortells R, Spaak P (2006). Genetic structure of parthenogenetic zooplankton populations - a conceptual framework. Arch Hydrobiol 167: 217-244.

Fryer G (1991). Functional morphology and the adaptive radiation of the Daphniidae (Branchiopoda: Anomopoda). Philos Trans $R$ Soc Lond B 331: 1-99.

Gómez A, Carvalho GR (2000). Sex, parthenogenesis and the genetic structure of rotifers: microsatellite analysis of contemporary and resting egg bank populations. Mol Ecol 9: 203-214.

Hebert PDN (1978). The population biology of Daphnia (Crustacea, Daphnidae). Biol Rev 53: 387-426.

Hebert PDN (1987). Genetics of Daphnia. In: Peters RH, De Bernardi R (eds). Daphnia. Mem Ist ital Idrobiol: Pallanza. pp 439-460.

Hebert PDN, Beaton MJ (1989). Methodologies for Allozyme Analysis Using Cellulose Acetate Electrophoresis. Helena Laboratories: Beaumont.

Hebert PDN, Finston TN, Footit R (1991). Patterns of genetic diversity in the sumac gall aphid, Melapis rhois. Genome 34: $757-762$.

Jacobs J (1990). Microevolution in predominantly clonal populations of pelagic Daphnia (Crustacea: Phyllopoda): selection, exchange, and sex. J Evol Biol 3: 257-282.

King CE (1980). The genetic structure of zooplankton populations. In: Kerfoot WC (ed). Evolution and Ecology of Zooplankton Communities. The University Press of New England: Hanover (NH). pp 315-329.

King CE (1993). Random genetic drift during cyclical ameiotic parthenogenesis. Hydrobiologia 255/256: 205-212.

Lande R (1996). Statistics and partitioning of species diversity and similarity among multiple communities. Oikos 76: 5-13.

Lynch M (1984). The genetic structure of a cyclical parthenogen. Evolution 38: 186-203.

Lynch M, Spitze K (1994). Evolutionary genetics of Daphnia. In: Real LA (ed). Ecological Genetics. Princeton University Press: Princeton. pp 109-128.

Miller MP (1997). Tools For Population Genetic Analyses (TFPGA), version 1.3. A windows program for the analysis of allozyme and molecular population genetic data. Computer software distributed by author.

Mort MA, Wolf HG (1986). The genetic structure of large-lake Daphnia populations. Evolution 40: 756-766.

Ortells R, Gomez A, Serra M (2006). Effects of duration the planktonic phase on rotifer genetic diversity. Arch Hydrobiol 167: 203-216.

Raymond M, Rousset F (1995). GENEPOP (version 1.2): population genetics software for exact tests and ecumenicism. Heredity 86: 248-249.

Rhomberg LR, Joseph S, Singh RS (1985). Seasonal variation and clonal selection in cyclically parthenogenetic rose aphids (Macrosiphium rosea). Can J Genet Cytol 27: 224-232. 
Rice WR (1989). Analysing tables of statistic tests. Evolution 43: 223-225.

Ruvinsky AO, Perelygin AA, Lobkov YI, Belyaev DY (1986). Factors organising and maintaining polymorphism in a cyclic parthenogen species: Daphnia pulex. Heredity 57: $15-22$.

StatSoft Inc (2001). STATISTICA (data analysis software system), version 6. www.statsoft.com

Sunnucks P, DeBarro PJ, Lushai G, Maclean N, Hales D (1997). Genetic structure of an aphid studied using microsattelites: cyclic parthenogenesis, differentiated lineages and host speciation. Mol Ecol 6: 1059-1073.
Tessier AJ, Young A, Leibold M (1992). Population dynamics and body size selection in Daphnia. Limnol Oceanogr 1: 1-13.

Vanoverbeke J, De Meester L (1997). Among-populational genetic differentiation in the cyclical parthenogen Daphnia magna (Crustacea, Anomopoda) and its relation to geographic distance and clonal diversity. Hydrobiologia 360: 135-142.

Weider LJ (1984). Spatial heterogeneity of Daphnia genotypes: vertical migration and habitat partitioning. Limnol Oceanogr 29: 225-235.

Weir BS, Cockerham CC (1984). Estimating F-statistics for the analysis of population structure. Evolution 38: 1358-1370. 